\title{
Effects of Extinction Context and Retrieval Cues on Alcohol Cue Reactivity Among Nonalcoholic Drinkers
}

\author{
Bradley N. Collins \\ University of Pennsylvania
}

\author{
Thomas H. Brandon \\ University of South Florida and \\ H. Lee Moffitt Cancer Center and Research Institute
}

\begin{abstract}
Pavlovian conditioning models have influenced the development of cue exposure treatments for drug abuse. However, poor maintenance of extinction performance (renewal) after treatment is a common problem. A treatment-analogue experiment tested the role of context in renewal, as well as a potential strategy for reducing renewal. Seventy-eight social drinkers completed extinction trials to reduce saliva and urge reactivity to alcohol cues and were randomly assigned to a renewal test in either the same context as extinction, a different context, or the different context containing a cue from the extinction context (E-cue). As predicted, the different context produced greater renewal than the same context and renewal was attenuated when the E-cue was present. These results offer preliminary evidence for the context dependence of extinction to alcohol cues and for the use of an extinction cue to improve the generalizability of exposure therapies.
\end{abstract}

Addiction models based on Pavlovian conditioning suggest that environmental cues previously associated with drug use can elicit reactivity that subsequently influences relapse (Drummond, Tiffany, Glautier, \& Remington, 1995; Niaura et al., 1988; Siegel, 1983; Wikler, 1965). Consequently, interventions based on Pavlovian extinction have been designed to reduce users' reactivity to drug cues and thereby minimize their probability of relapse. Extinction occurs after repeated presentations of drug-related cues (cue exposure) paired with the prevention of drug selfadministration (response prevention). With repeated trials, a user's reactivity to the drug-relevant cues (e.g., craving to use the drug) decreases. One obstacle to the effectiveness of these treatments, however, is the instability of extinction performance across posttreatment contexts. Extinction appears to be context specific and a renewal of reactivity occurs when a client is exposed to drug-use stimuli in a context that is distinct from the treatment context (Bouton, 1988). Subsequently, conditioned reactivity to drug-use

Bradley N. Collins, Department of Psychiatry, University of Pennsylvania; Thomas H. Brandon, Department of Psychology, University of South Florida, and H. Lee Moffitt Cancer Center and Research Institute, Tampa, Florida.

Much of the research reported was conducted while the authors were at the State University of New York at Binghamton. We thank Stephen A. Lisman, Paul Stasiewicz, and Norman A. Spear for their suggestions and assistance with this project. We also thank Dawn Chirichella, Stacey Esolen, and Melissa Syzmanski for their assistance with research participants and data entry.

Correspondence concerning this article should be addressed to Bradley N. Collins, Department of Psychiatry, University of Pennsylvania, 3535 Market Street, Suite 4100, Philadelphia, Pennsylvania 19104 or to Thomas H. Brandon, H. Lee Moffitt Cancer Center, 4115 East Fowler Avenue, Tampa, Florida 33617. E-mail: bnc@mail.med.upenn.edu or brandont@ moffitt.usf.edu cues are renewed and the risk of relapse increases. The current study examined the renewal effect following extinction of alcoholcue reactivity among moderate-to-heavy-consuming social drinkers in a laboratory setting. Of particular interest were the effects of an extinction-context memory retrieval cue (E-cue) designed to attenuate this renewal.

Pavlovian conditioning models suggest that during substance self-administration, otherwise neutral stimuli become paired or associated with the unconditioned, pharmacological effects of the drug (e.g., tachycardia or euphoria). Over time, the previously neutral conditioned stimuli (CSs) develop the capacity to elicit physiological conditioned responses (CRs) in the absence of drug ingestion (Siegel, 1983; Stewart, DeWit, \& Eikelboom, 1984; Wikler, 1965). Data have consistently suggested that exteroceptive environmental CSs (e.g., drug paraphernalia) can cause conditioned cue reactivity in alcoholics, opiate addicts, and smokers (Brandon, Piasecki, Quinn, \& Baker, 1995; Rohsenow, Niaura, Childress, Abrams, \& Monti, 1990-1991; Wikler, 1948). Researchers also have demonstrated that interoceptive CSs (e.g., negative affect; drug-related imagery) cause CRs in smokers, alcoholics, and opiate addicts (Brandon et al., 2002; Childress, McLellan, Natale, \& O'Brien, 1987; Collins, Copeland, Quinn, \& Brandon, 1994; Litt, Cooney, Kadden, \& Gaupp, 1990; Payne, Schare, Levis, \& Colletti, 1991; Tiffany \& Drobes, 1990). CRs are thought to contribute to drug use maintenance (e.g., Rohsenow et al., 1994) as well as to relapse (Marlatt, 1985; Mermelstein \& Lichtenstein, 1983; Niaura et al., 1988; Wise, 1988). Consequently, extinction-based cue-exposure treatments for substance abuse and dependence have been developed.

Cue-exposure treatments are based on Pavlovian-conditioning models and are thought to hold promise in the treatment of drug abuse and dependence (Monti \& Rohsenow, 1999). Recently, cue-exposure treatment studies have demonstrated posttreatment 
decreases in drug cravings or consumption (Childress, McLellan, \& O’Brien, 1986; Drummond \& Glautier, 1994; McLellan, Childress, Ehrman, O’Brien, \& Pashko, 1986; Monti et al., 1993; O'Brien, Childress, McLellan, \& Ehrman, 1990; Rankin, Hodgson, \& Stockwell, 1983; Sitharthan, Sitharthan, Hough, \& Kavanagh, 1997; Stasiewicz et al., 1997). However, long-term outcomes remain modest. Likewise, its utility as an adjunct to state-of-the-art cognitive-behavioral relapse prevention has been questioned (Niaura et al., 1999). It is arguable that these limitations can be attributed to the minimal attention paid to context effects (Brandon et al., 1995; Childress et al., 1986; Powell, 1995; Rodriguez, Craske, Mineka, \& Hladek, 1999).

The conditioning literature has long suggested that extinction, unlike acquisition, is unstable and does not generalize well across contexts (Bouton \& Bolles, 1985; Pavlov, 1927/1960). Thus, behavior following cue exposure or extinction is likely to be disrupted by context change (Bouton \& Swartzentruber, 1991). Contexts include stimuli as diverse as physical environments, drug states, emotions, the passage of time (Bouton \& Swartzentruber, 1991), and cognitions (Bradizza, Stasiewicz, \& Maisto, 1994). The hypothesized mechanism by which contexts control responding to CSs may be through retrieving memory of a CS's association with the unconditioned stimulus (Bouton \& Bolles, 1985; Miller \& Schachtman, 1985; Spear, 1973, 1981). Thus, when a context is similar to the extinction context, CSs are more likely to elicit extinction performance, and slow reacquisition of the CR is typically observed. Conversely, when a context is similar to the original conditioning context, CSs are more likely to elicit renewed conditioned performance or "renewal" (Bouton \& Swartzentruber, 1991).

The renewal effect is one phenomenon that demonstrates the context-dependence of extinction (Bouton, 1988; Tobeña et al., 1993). After extinction, renewed responding to the CS can occur if the CS is presented in either a context similar to that of original conditioning or a novel context. This effect has been shown in animal studies (Bouton \& King, 1983; Bouton \& Swartzentruber, 1989; Cunningham, 1979; Hanford, Mulvaney, \& Kelfer, 1980; Lovibond, Preston, \& Mackintosh, 1984) as well as in human anxiety studies (Mineka, Mystkowski, Hladek, \& Rodriguez, 1999; Rodriguez et al., 1999). It has also been demonstrated that the renewal effect can occur regardless of the number of extinction trials (Bouton \& Swartzentruber, 1989).

The animal literature has extended research on context effects by demonstrating strategies that minimize extinction instability. For example, in an appetitive-conditioning paradigm, Brooks and Bouton (1994) demonstrated attenuation of renewal by adding a stimulus from the previous extinction context into the renewal test context. During renewal testing, the presence of this "extinction context memory-retrieval cue" (E-cue) produced less renewal than testing without the E-cue, testing with a novel cue presented during the renewal test, or testing with an equally familiar CS that had been presented only during conditioning. When presented alone, the E-cue did not act as either a conditioned excitor or inhibitor, suggesting that it worked by retrieving a memory of extinction. Applied to the area of addiction treatment, an E-cue presented in a former drug-using context may evoke extinction performance by eliciting memories of the extinction/cue-exposure treatment context.

The primary aim of this study was to test whether Brooks and Bouton's (1994) animal research demonstrating the role of context on the renewal effect would generalize to a sample of moderateto-heavy-consuming social drinkers. Although the design of this study was modeled after Bouton's research, there was one key difference. Whereas experimenters using animal extinction preparations condition cue reactivity in vitro prior to extinguishing the $\mathrm{CR}$, human clinical studies presume that conditioning has already occurred in the natural environment. Thus, the bulk of the experiment comprised alcohol CR extinction trials and a renewal test. We measured participants' saliva and urge reactivity at baseline, pretest, and during massed extinction trials. Subsequent to extinction and a rest period, reactivity to alcohol cues was measured again during a renewal test conducted in either the same context (SC) as extinction, a different context than extinction (DC), or a different context plus an E-cue (DC + E-cue), as determined by randomization. After equivalence between groups was established from baseline through extinction, analyses focused on predicted group differences in reactivity to alcohol cues that would emerge during the renewal test. Thus, the context of the renewal test constituted the experimental manipulation.

It was hypothesized that following extinction, between-groups differences in cue reactivity (as measured by self-reported urge and salivation) would emerge across conditions on the renewal test that could be attributed to context change and the presence of the E-cue. It was predicted that a monotonic relationship would emerge across conditions reflecting strength of renewed reactivity on both dependent measures as follows (see Table 1): the least reactivity in the SC group; an intermediate level of reactivity in the $\mathrm{DC}+\mathrm{E}$-cue group despite a context change due to the presence of the E-cue during the renewal test; and the greatest reactivity in the DC group due to the change of context at the renewal test $(\mathrm{SC}<$ $\mathrm{DC}+$ E-cue $<\mathrm{DC})$.

Table 1

Experimental Design and Predictions of Performance at Renewal Test

\begin{tabular}{lclcc}
\hline \multicolumn{1}{c}{ Group } & Baseline and pretest & Extinction & Renewal test & Renewal phase prediction \\
\hline SC & A & A + E-cue & A & Maintained extinction \\
DC + E-cue & A & B + E-cue & A + E-cue & Attenuated renewal \\
DC & A & B + E-cue & A & Renewal of reactivity \\
\hline
\end{tabular}

Note. The rooms used for Context A (A) and Context B (B) were counterbalanced within conditions. Although equivalent procedures were used across conditions prior to the renewal test, random assignment to condition occurred prior to the baseline assessment. SC $=$ same context; DC $=$ different context; E-cue $=$ extinction retrieval cue. 


\section{Method}

\section{Participants}

Recruitment. Two hundred ninety-three volunteer respondents were screened from the university student population. This sample included 177 students enrolled in Introductory Psychology courses, 85 volunteers from the university Greek system, and 31 university students who called the experimenter in response to fliers inviting "beer drinkers interested in learning more about a research opportunity." These volunteers completed the Quantity Frequency Variability Index (QFV; Calahan, Cisin, \& Crossley, 1969), which identifies respondents' drinking patterns. During a pilot study, we had determined that among college-age individuals, extinction to alcohol cues was related to heavier and more frequent consumption of alcohol. Thus, for the screening, we attempted to identify moderate-toheavy social drinkers on the basis of self-report ratings on the QFV. Inclusion criteria for recruitment in the present study were defined to include those who drank at least three to four cans of beer per drinking occasion and who drank at least one to two times per week. Respondents were included if they stated that they were either most familiar or equally familiar with beer compared with other alcohol beverages (wine, liquors). After the QFVs were scored, screening participants who met inclusion criteria were recruited over the phone. To minimize a potential demand effect, the experimenter stated that the purpose of the study was to assess people's ability to rate the sight and smell of different beers over many trials. Interested individuals were offered either $\$ 15$ or class research credit for participating and were scheduled for an experimental session.

Participant sample. Of the 293 individuals screened, the 112 who met screening criteria were randomly assigned to the three experimental conditions and scheduled for the study. However, 29 participants failed to appear, one dropped out before completing the procedure because of a scheduling conflict, and another four were dropped from the analyses because of experimenter error or equipment malfunction. The remaining 78 participants were included in subsequent analyses: SC group $(n=27)$, DC group $(n=26)$, DC + E-cue group $(n=25)$.

\section{Independent Variables}

Context. Two testing rooms were used to represent two unique contexts, and were counterbalanced within conditions. The two contexts were constructed to be as different as possible to maximize the expression of context-dependent learning (Mineka et al., 1999). Both rooms had a oneway mirror for continuous participant observation; however the rooms differed in dimension, decor, odor, ambient temperature, lighting, furniture, experimental equipment, and location (first vs. third floors).

E-cue. A novelty pencil with a textured grip and weighted eraser coupled with a neon green plastic clipboard served as the E-cue. Participants used these instruments to complete their urge ratings. The E-cue was present in the extinction context across all conditions and during the renewal test for only the DC + E-cue group (see Table 1). During the pretest for all conditions and during the renewal test for the SC and DC conditions, participants completed urge ratings with a standard black ballpoint pen with the forms placed directly on the desk surface. Specifically, the novelty pencils were approximately $3 \mathrm{~cm}$ shorter than a new, standard pencil. They had a bright variety of colors painted length-wise and had multicolored, textured spirals carved into the wood where a writer would grip it. For an eraser, a heavy, pink, teddy bear eraser was attached to the end of the pencil that threw the center of weight toward that end of the pencil. The experimenter placed the urge-rating form on the neon green clipboard during the extinction trials (and during the renewal test for the DC + E-cue group). Participants were not instructed to attend to either pencil or clipboard so as to minimize the threat of potential demand effects. However, the retrieval cue was intended to be a salient E-cue, as it targeted both tactile and visual sensory modalities and was used each time participants completed the urge-rating scales throughout the extinction phase.

\section{Dependent Measures}

Salivation. Salivation has repeatedly demonstrated its sensitivity to alcohol cues (Cooney, Baker, Pomerleau, \& Josephy, 1984; Monti et al., 1987; Newlin, Hotchkiss, Cox, Rauscher, \& Li, 1989; Pomerleau, Fertig, Baker, \& Cooney, 1983; Rohsenow et al., 1992). The human salivary response has also been demonstrated to extinguish in response to food cues (Corty \& Coon, 1995) and following cue exposure to alcohol cues (McCusker \& Brown, 1995). Saliva was measured by weighing three dental rolls that participants had placed in their mouth during each trial. Participants inserted one under their tongue, and two on either side of their mouth between their lower lip and gum line. After each trial, participants sealed the rolls inside plastic bags to be weighed. Weight differences of the rolls indicated change in saliva production across baseline, pretest, extinction, and renewal testing phases of the experiment. This procedure has been used effectively in previous studies (e.g., Corty \& Coon, 1995; Rohsenow et al., 1992).

Urge self-report. On a 7-point Likert scale, participants completed self-reported ratings of their desire to consume the beer, their ability to refuse a drink if offered one presently, and how much they enjoyed the sight and smell of the beer. The last scale was included to parallel the rationale described to participants at recruitment and maximized the chance that participants would attend to the sight and odor of the beer. Previous research has suggested that two- or three-item item urge measures are reliable and effective in measuring urges or desire to use a substance (Kozlowski, Pillitteri, Sweeney, Whitfield, \& Graham, 1996).

\section{Procedure}

Participants were asked to abstain from drinking alcohol for $24 \mathrm{hr}$ prior to their experimental session and were randomly assigned to one of three groups. All sessions took place between midafternoon and early evening, as pilot testing indicated differential extinction performance during earlier and later periods. Table 2 outlines the procedure timeline.

Table 2

Procedure Timeline

\begin{tabular}{|c|c|c|c|c|c|c|c|c|}
\hline Group & Consent & $\begin{array}{l}\text { Preexposure } \\
\text { phase }\end{array}$ & $\begin{array}{c}\text { Baseline } \\
\text { phase }\end{array}$ & $\begin{array}{l}\text { Pretest } \\
\text { phase }\end{array}$ & $\begin{array}{c}\text { Break/ } \\
\text { move }\end{array}$ & $\begin{array}{l}\text { Extinction } \\
\text { phase }\end{array}$ & $\begin{array}{l}\text { Distraction/ } \\
\text { rest phase }\end{array}$ & $\begin{array}{l}\text { Renewal } \\
\text { test phase }\end{array}$ \\
\hline $\mathrm{SC}$ & WR & $\begin{array}{l}A \text { and } B \\
3 \text { min each }\end{array}$ & $\begin{array}{l}\mathrm{A} \\
3 \min \end{array}$ & $\begin{array}{l}A \\
5 \text { min }\end{array}$ & $5 \mathrm{~min}$ & $\begin{array}{l}A+\text { E-cue } \\
35-50 \text { min }\end{array}$ & $\begin{array}{l}\text { WR } \\
25 \text { min }\end{array}$ & $\begin{array}{l}\mathrm{A} \\
2 \times 5 \min \end{array}$ \\
\hline $\mathrm{DC}+$ E-cue & WR & $\begin{array}{l}A \text { and } B \\
3 \text { min each }\end{array}$ & $\begin{array}{l}\mathrm{A} \\
3 \text { min }\end{array}$ & $\begin{array}{l}\mathrm{A} \\
5 \mathrm{~min}\end{array}$ & $5 \mathrm{~min}$ & $\begin{array}{l}\mathrm{B}+\text { E-cue } \\
35-50 \mathrm{~min}\end{array}$ & $\begin{array}{l}\text { WR } \\
25 \text { min }\end{array}$ & $\begin{array}{l}A+E-\text { cue } \\
2 \times 5 \text { min }\end{array}$ \\
\hline $\mathrm{DC}$ & WR & $\begin{array}{l}A \text { and } B \\
3 \text { min each }\end{array}$ & $\begin{array}{l}\mathrm{A} \\
3 \text { min }\end{array}$ & $\begin{array}{l}A \\
5 \text { min }\end{array}$ & $5 \mathrm{~min}$ & $\begin{array}{l}\mathrm{B}+\text { E-cue } \\
35-50 \text { min }\end{array}$ & $\begin{array}{l}\text { WR } \\
25 \mathrm{~min}\end{array}$ & $\begin{array}{l}\mathrm{A} \\
2 \times 5 \min \end{array}$ \\
\hline
\end{tabular}

Note. $\mathrm{SC}=$ same context $\mathrm{WR}=$ waiting room; $\mathrm{E}-\mathrm{cue}=$ extinction retrieval cue; $\mathrm{A}=$ Context $\mathrm{A} ; \mathrm{B}=\mathrm{Context} \mathrm{B} ; \mathrm{DC}=$ different context. 
Consent and preexposure phase. On arrival to their session, participants received a detailed introduction to the study and completed an informed consent form in the waiting room. The experimenter explained to participants that we were interested in how people react to and rate different brands of beer after multiple presentations of the same beer (with the participant unaware of the particular brand). After the introduction, the experimenter took participants to both rooms for the 6-min context preexposure phase. They were instructed to sit in each room for $3 \mathrm{~min}$ to become "acclimated and relaxed" in rooms where they "would potentially be sitting during the experiment." During this time, they were asked to become familiar with the room in as much detail as possible. At the end of $2 \mathrm{~min}$, participants were instructed by means of an intercom to write on a blank sheet of paper all of the details about the room that they could in $1 \mathrm{~min}$. The purpose of the exercise was to ensure that participants were attending to the most salient contextual cues in each room. The preexposure potentially minimizes post hoc explanations of reactivity during testing that are attributable to the novelty of stimuli in either room.

Baseline and pretest phases. All participants sat in Context A for baseline and the cue-reactivity pretest. During the baseline phase, they were led to the room by the experimenter, instructed to relax "for a couple of minutes" and to await further instructions over the intercom. After participants placed the three dental rolls in their mouth, they sat quietly for $3 \mathrm{~min}$. Then participants removed the dental rolls from their mouth and placed them in a sealed plastic bag as instructed over the intercom. They were further instructed to complete their urge ratings and then to drink the ounce of water provided.

Following a 2-min-rest period, the experimenter again instructed participants to insert dental rolls into their mouth. The experimenter instructed them to lift the opaque container that concealed the beer can and beer-filled cup. Then the audiotaped instructions prompted the participants to lift the cup to their nose and sniff for $5 \mathrm{~s}$. Participants had been instructed not to consume the beer, and none did. There were 13 such 5-s signals over the 3 min trial ( $65 \mathrm{~s}$ of direct olfactory exposure), with an 8-s latency to the first signal and an 8-s interval between signals. A similar procedure has been demonstrated to elicit cued responding in a previous study (Rohsenow et al., 1992). At the conclusion of the pretest, participants put the rolls in another bag, sealed it, and completed urge ratings.

Extinction phase. In general, this procedure was modeled after research by Rohsenow et al. (1992), with some pragmatic modifications. A pilot study suggested that this procedure was effective in extinguishing cue reactivity to alcohol cues in a similar sample.

At the beginning of the extinction phase, an experimenter led the participants from the pretest room to the alternative room for the extinction trials. If participants were in the SC group, they were instructed to "stretch their legs" in the waiting room for approximately $5 \mathrm{~min}$ before returning to the same room (this was the equivalent time it took the participants to walk between the alternative rooms and get settled). In all conditions during the extinction phase, the E-cue was present.

Once seated in the extinction context, participants followed the same procedure as they did during the pretest. Prior to each trial, the experimenter would enter the experimental room to bring the next self-report rating scale and the bag for the dental rolls, fill the intertrial water cup to the $1-\mathrm{oz}$ line, and check that the beer level was maintained to the beer cup-fill line (to verify that the participant had not consumed beer). The experimenter would then leave for the adjacent observation room where audiotaped instructions over an intercom told the participant to insert the dental rolls, sniff the beer, complete the rating scale, and so forth. Each exposure trial offered approximately $5 \mathrm{~min}$ of visual exposure to the beer, as the beer was visible during direct olfactory exposure as well as during the time the participants completed the urge-rating scales. Each trial included 13 signals totaling $65 \mathrm{~s}$ of direct olfactory exposure to the beer. This procedure was repeated for at least 7 extinction trials. Because of time constraints, experimenters were precluded from running more than 10 trials. Thus, the following procedure was adopted:
All participants received at least 7 extinction trials. Thirty-three (42\%) reached the extinction criterion (return to baseline urge) after 7 trials (totaling approximately $35 \mathrm{~min}$ of alcohol-cue exposure). Those participants whose self-reported urge ratings had not returned to baseline by the 7 th trial received up to 3 additional extinction trials. An additional 8 (10\%) reached criterion by the 10th trial (approximately $50 \mathrm{~min}$ of alcohol-cue exposure) for a total of $52 \%$ who reached criterion by the end of the extinction phase. No participants received more than 10 extinction trials. Twenty-one $(27 \%)$ participants did not reach criterion after 10 trials, and $16(21 \%)$ stopped the extinction phase after 9 extinction trials at their request because of scheduling conflicts despite not having met criterion. There were no significant differences between groups in terms of number of extinction trials.

Rest-distraction phase. After the extinction phase, participants were taken back to the waiting room where they were offered a bathroom break and subsequently asked to work a crossword puzzle. The total time of the rest period was $25 \mathrm{~min}$. The crossword puzzle was designed to distract participants from mentally attending to or rehearsing contextual cues from the extinction context. During a pilot study, it was determined that $25 \mathrm{~min}$ was the minimum time needed to consistently observe the renewal effect.

Renewal test phase. When they completed the rest period, participants in the DC and DC + E-cue groups returned to the pretest context for the renewal test. The renewal test was conducted in the same room used during extinction for the SC group and in different rooms than extinction for the $\mathrm{DC}$ and DC $+\mathrm{E}$-cue groups. The E-cue was present during the renewal test only for the DC + E-cue group (see Table 1). The renewal phase consisted of two renewal test trials using the same procedure as the extinction phase trials. Following the renewal phase, participants were debriefed.

\section{Results}

\section{Participant Characteristics and Group Equivalence}

Most participants were college-aged, with $89 \%$ between the ages of 18 and 22 years $(M=21.13$ years). The sample was primarily Caucasian $(88 \%)$ and female $(53 \%)$, with no gender differences in any of the demographic or alcohol history characteristics. On the QFV, $88.5 \%$ of respondents reported that they were more familiar with beer than other forms of alcohol. The QFV alcohol consumption data revealed that $92.4 \%$ of the sample consumed five to six cans of beer at least every other time they drank and that $88.4 \%$ reported drinking at least three to four times per week. These data suggest a sample composed of a majority of moderate-to-heavy drinkers. Forty-five percent of the participants also reported being unable to adhere to the request to abstain from drinking within $24 \mathrm{hr}$ prior to their experiment session.

Chi-square tests and one-way analyses of variance (ANOVAs) were calculated for the major demographic and alcoholconsumption-pattern variables. No significant differences emerged across conditions, and there was no significant difference between those who met extinction criteria and those who did not. Furthermore, during the debriefing, only 1 participant accurately reported understanding the nature of the experiment in terms of hypothesizing the role of context in contributing to "desire" to drink. Thus, it was unlikely that differences across conditions were the result of demand effects.

\section{Reliability and Convergent Validity of Dependent Measures}

The three-item alcohol-urge-rating scale's internal consistency reliability was $\alpha=.83$. This was determined on the basis of 
responses at the pretest, when participants were presented with alcohol cues for the first time. Test-retest reliability among participants in the SC group (no context manipulation) between the pretest and the first extinction trial was high, $r(25)=.88, p<.05$. The alcohol-urge-rating scale and saliva weights showed modest correlations: baseline, $r(76)=.21, p=.06$; pretest, $r(76)=.23$, $p=.05$; last extinction trial, $r(76)=.12, p=.31$; renewal, $r(76)=.22, p=.05$.

\section{Reactivity Equivalence Across Groups Through the Extinction Phase}

Table 3 displays the reactivity scores from baseline through the renewal trials. Analyses were conducted to test for the equivalence of groups from baseline through extinction. There were no significant differences in mean saliva weights or urge across conditions at baseline. After establishing equivalence of groups at baseline, 2 (time) $\times 3$ (condition) mixed ANOVAs were conducted to test whether saliva weight and urge means increased from baseline to pretest. For saliva, we found the predicted increase in saliva weight from baseline to pretest, $F(1,75)=13.28, p<.001$, but no main effect for condition, and no Condition $\times$ Time interaction, $(p s>$ .30). Likewise, between baseline and pretest trials, there was an increase in urge ratings, $F(1,75)=69.41, p<.001$, but no main effect for condition and no Condition $\times$ Time interaction, $(p s>$ $.55)$. These results suggested equivalent increases in saliva reactivity across groups from baseline to the pretest trials, as predicted.

To test the equivalence of extinction across groups, we conducted $2 \times 3$ mixed ANOVAs across conditions between the pretest and last extinction trial on both dependent measures. For saliva, there was the expected decrease during the course of the extinction trials, $F(1,75)=47.81, p<.001$, but no main effect for condition and no Condition $\times$ Time interaction $(p s>.20)$. Similarly, we found that urge scores decreased over time, $F(1$, $75)=19.79, p<.001$, but there was no main effect for condition, and no Condition $\times$ Time interaction, $(p s>.30)$. Therefore, the urge and saliva results indicate that both cue reactivity and extinction occurred and that the three conditions produced similar patterns of reactivity and extinction.

\section{Context Effects}

It was hypothesized that reactivity differences would emerge across conditions between the last extinction trial and the renewal test. Specifically, it was predicted that the least reactivity would be found in the SC condition, the greatest in the DC condition, and an intermediate level of reactivity would be found in the DC + E-cue condition. To test this hypothesis, we conducted analyses of covariance (ANCOVA) using either saliva or urge collected at the renewal test as the dependent variable, with the same measure collected at the last extinction trial as the covariate. Contrast analyses (Rosenthal \& Rosnow, 1985) were conducted to test the prediction that the covariate-adjusted means would align in the predicted monotonic sequence (SC $<$ DC + E-cue $<$ DC). This prediction was supported for saliva reactivity, $F(1,74)=9.00$, $p<.01$, as well as for urge, $F(1,73)=8.91, p<.01$. The covariate-adjusted means for both measures are presented in Table 4 .

\section{Discussion}

This study provided an analog test of the role of extinction context in alcohol-cue exposure. Foremost, results from this experiment offered some compelling preliminary support for the influence of context on postextinction reactivity to alcohol cues among moderate-to-heavy social drinkers. Specifically, betweengroup means on both dependent measures emerged in predicted directions at the renewal test: There was greater renewal when the test occurred in a different context than when the test occurred in the same context as extinction. This observation is in concert with animal studies on the renewal effect (Bouton \& King, 1983; Bouton \& Swartzentruber, 1989; Cunningham, 1979; Hanford et al., 1980; Lovibond et al., 1984) as well as human studies investigating the renewal of fear among spider phobics (Mineka et al., 1999; Rodriguez et al., 1999). Support for the renewal effect highlights the limited generalizability of extinction following cue exposure and response prevention.

Perhaps more important, however, was the observation that renewal was attenuated when an E-cue was present during the

Table 3

Reactivity From Baseline Through Renewal Test

\begin{tabular}{|c|c|c|c|c|c|c|c|c|c|}
\hline \multirow[b]{2}{*}{ Condition } & \multirow[b]{2}{*}{$n$} & \multicolumn{2}{|c|}{ Baseline } & \multicolumn{2}{|c|}{ Pretest } & \multicolumn{2}{|c|}{$\begin{array}{c}\text { Last } \\
\text { extinction } \\
\text { trial }\end{array}$} & \multicolumn{2}{|c|}{$\begin{array}{c}\text { Renewal } \\
\text { trials }\end{array}$} \\
\hline & & $M$ & $S D$ & $M$ & $S D$ & $M$ & $S D$ & $M$ & $S D$ \\
\hline \multicolumn{10}{|l|}{ Saliva weight (mg) } \\
\hline $\mathrm{SC}$ & 27 & 7.35 & 1.87 & 7.89 & 1.66 & 7.34 & 1.74 & 7.27 & 1.80 \\
\hline DC & 26 & 7.60 & 1.69 & 7.77 & 1.57 & 6.97 & 1.35 & 7.52 & 1.45 \\
\hline $\mathrm{DC}+\mathrm{E}$-cue & 25 & 7.35 & 1.89 & 7.80 & 2.09 & 6.78 & 1.72 & 7.11 & 1.59 \\
\hline \multicolumn{10}{|c|}{ Self-reported urge rating ( $0-6$ scale) } \\
\hline $\mathrm{SC}$ & 27 & 1.46 & 1.07 & 2.51 & 1.08 & 1.72 & 1.27 & 1.69 & 1.42 \\
\hline DC & 26 & 1.83 & 1.59 & 2.64 & 1.51 & 1.77 & 1.32 & 2.57 & 1.52 \\
\hline $\mathrm{DC}+\mathrm{E}$-cue & 25 & 1.86 & 1.29 & 2.81 & 1.50 & 2.44 & 1.77 & 2.56 & 1.69 \\
\hline
\end{tabular}

Note. From baseline through last extinction trial, the only significant effect was for time $(p \mathrm{~s}<.001)$, indicating group equivalence in reactivity and extinction. $\mathrm{SC}=$ same context; $\mathrm{DC}=$ different context; E-cue $=$ extinction retrieval cue. 
Table 4

Covariate-Adjusted Means $\times$ Condition, Reflecting Reactivity at the Renewal Test

\begin{tabular}{lcccccc}
\hline & \multicolumn{2}{c}{$\begin{array}{c}\text { Saliva weight } \\
(\mathrm{mg})\end{array}$} & & \multicolumn{2}{c}{$\begin{array}{c}\text { Self-reported urge } \\
\text { rating (0-6 scale) }\end{array}$} \\
\cline { 2 - 3 } Condition & $M$ & & & & & $S$ \\
\hline SC & 7.00 & 0.14 & & 1.91 & 0.20 \\
DC + E-cue & 7.35 & 0.14 & & 2.11 & 0.21 \\
DC & 7.57 & 0.14 & & 2.74 & 0.20 \\
\hline
\end{tabular}

Note. Both contrast tests were significant $(p s<.01) . \mathrm{SC}=$ same context; $\mathrm{DC}=$ different context; E-cue $=$ extinction retrieval cue.

renewal test. These results are also consistent with those in the animal literature (Brooks \& Bouton, 1994; Brooks, Palmatier, Garcia, \& Johnson, 1999). In a design similar to the present one, Brooks and Bouton (1994) demonstrated that following extinction, rats tested in postextinction contexts demonstrated less renewal if an E-cue was present during the test compared with rats tested when an E-cue was not present. These replications of the animal literature are especially impressive given the fundamental differences in the experimental designs of the animal studies compared with the present one. Unlike the animal studies in which subjects' conditioning history is controlled by the experimenter, participants in the present study entered the experiment with a range of uncontrolled and unknown conditioning histories with alcohol. Despite this "noise," extinction context effects emerged.

Thus, not only do the results highlight the role of context effects that may contribute to relapse following alcohol-cue-exposure therapy, but they also provide some preliminary implications for future treatment-outcome research. For example, such evidence implies that cue-exposure therapies in general could be modified to increase extinction generalizability - and this need not be limited to treatment for problem drinkers. Theoretically, the use of an E-cue could be extended to the treatments of other substances of abuse as well as to other disorders treated by exposure and response prevention methods (e.g., anxiety disorders).

There are additional strategies for achieving renewal attenuation. One strategy would be to extinguish cue reactivity across multiple contexts. For example, Gunther, Denniston, and Miller (1998) demonstrated attenuated renewal when extinction trials occurred over multiple contexts. Another strategy to attenuate renewal would be to make the extinction context identical to the conditioning one or to include in vivo exposure as a means to minimizing the probability of relapse (Pead et al., 1993; Powell, 1995). However, because alcohol abusers drink in multiple conditioning contexts, we would predict: (a) Exposing them during extinction to all potential relevant conditioning contexts in vivo would be impractical and (b) exposing them across multiple extinction contexts would be insufficient to attenuate renewal. Indeed, Gunther et al. (1998) provide support for this second prediction, as they observed attenuated renewal only when conditioning occurred in a single context, but not when multiple conditioning contexts were used.

Thus, future clinical research could build upon the preliminary evidence suggesting that E-cues may attenuate renewal. One example would be to give problem drinkers E-cues to remind them of the extinction-treatment context when confronted with substancerelated cues in a posttreatment context. Potential ideas along this line would include expansion of existing techniques (e.g., AA tokens). Instead of using tokens as a long-term reward, one could explore using a similar item following cue exposure that could function not only as positive reinforcement for treatment gains but also as an E-cue. Similar to exploring the use of physical extinction context cues, researchers could investigate from a Pavlovian perspective the effectiveness of cognitive-behavioral relapseprevention-skills-training approaches used in conjunction with exposure methods. Perhaps cognitive-behavioral therapy components already provide exemplars of cognitive extinction context cues (Bradizza et al., 1994). For example, existing treatment approaches teach patients to prepare for high-risk situations (most often previous conditioning contexts) by identifying triggers (alcohol-related cues) and engaging in alternative coping skills. Some of the cognitive coping skills may serve to implicitly remind patients of the treatment context (e.g., "this urge will pass..."). The function of such physical and cognitive extinction cues could be systematically studied in terms of their impact on renewal and subsequent relapse.

Some limitations in this experiment should be highlighted. First, the experimental design included a potential confound in that participants in the SC condition received more exposure to Context A than did the other two groups. Thus, the greater renewal found in the DC and DC + E-cue conditions could have somehow resulted from the greater novelty of the renewal context in those conditions compared with the SC condition. However, this concern is minimized by the observed effect of the E-cue, which cannot be explained by this potential confound. Nevertheless, future studies should implement a design that equates exposure to the two contexts.

Another limitation was that only $52 \%$ of participants reached the extinction criterion of return to baseline urge rating. It is possible that a greater number of extinction trials would have produced a higher rate of complete extinction in this sample of moderate-toheavy social drinkers. However, it may also be that our extinction criterion of return to baseline urge was unrealistically stringent given the drinking experience of the sample and the limited magnitude of the exposure intervention provided in this analogue study. Indeed, investigating potential mediators of cue reactivity (e.g., neurobiological mechanisms) were beyond the scope of this study but could be studied in future research to gain a better understanding of individual differences in extinction performance. Regardless of the explanation, that the context effects were found despite the use of this extinction criterion demonstrates the robustness of the context effect on renewal.

Other limitations of the study reflect its analogue nature. These include the use of social drinkers not in treatment (although nearly half were unable to abstain for $24 \mathrm{hr}$ ), a short extinction intervention limited to visual and olfactory alcohol cues, and only an immediate assessment of extinction performance. A future, more externally valid study could use more complex cues (including affective and cognitive cues) and perhaps include training in cognitive and behavioral coping skills to enhance the extinction or treatment process (see Cooney, Litt, Morse, Bauer, \& Gaupp, 1997; Rohsenow et al., 1994). Future studies should also move toward closer representations of actual treatment of alcoholics or problem drinkers, including a more extended follow-up. If such 
studies replicate the finding that renewal of alcohol cravings is attenuated by the use of extinction context memory-retrieval cues, relapse-prevention strategies may be developed to adapt the technique to true clinical settings, thereby enhancing the generalizability of cue exposure treatment outcomes.

\section{References}

Bouton, M. E. (1988). Context and ambiguity in the extinction of emotional learning: Implications for exposure therapy. Behaviour Research and Therapy, 26, 137-149.

Bouton, M. E., \& Bolles, R. C. (1985). Contexts, event-memories, and extinction. In P. D. Balsam \& A. Tomie (Eds.), Context and learning (pp. 133-166). Hillsdale, NJ: Erlbaum.

Bouton, M. E., \& King, D. A. (1983). Contextual control of the extinction of conditioned fear: Tests for the associative value of the context. Journal of Experimental Psychology: Animal Behavior Processes, 9, 248-265.

Bouton, M. E., \& Swartzentruber, D. (1989). Slow reacquisition following extinction: Context, encoding, and retrieval mechanisms. Journal of Experimental Psychology: Animal Behavior Processes, 15, 43-53.

Bouton, M. E., \& Swartzentruber, D. (1991). Sources of relapse after extinction in Pavlovian and instrumental learning. Clinical Psychology Review, 11, 123-140.

Bradizza, C. M., Stasiewicz, P. R., \& Maisto, S. A (1994). A conditioning reinterpretation of cognitive events in alcohol and drug cue exposure. Journal of Behavior Therapy and Experimental Psychiatry, 25, 15-22.

Brandon, T. H., Collins, B. N., Copeland, A. L., Quinn, E. P., Juliano, A. B., \& Lazev, A. B. (2002). Negative affect induction enhances smoking urge and measures of smoking topography. Manuscript in preparation.

Brandon, T. H., Piasecki, T., Quinn, E. P., \& Baker, T. B. (1995). Cue exposure treatment in nicotine dependence. In D. C. Drummond, S. Tiffany, S. Glautier, \& B. Remington (Eds.), Addictive behaviour: Cue exposure theory and practice (pp. 211-227). New York: Wiley.

Brooks, D. C., \& Bouton, M. E. (1994). A retrieval cue for extinction attenuates response recovery (renewal) caused by a return to the conditioning context. Journal of Experimental Psychology, 20, 366-379.

Brooks, D. C., Palmatier, M. I., Garcia, E. O., \& Johnson, J. L. (1999). An extinction cue reduces spontaneous recovery of a conditioned taste aversion. Animal Learning and Behavior, 27, 77-88.

Calahan, D., Cisin, I. H., \& Crossley, H. M. (1969). American Drinking Practices: A national study of drinking behaviors and attitudes (Monograph No. 6). New Brunswick, NJ: Rutgers Center of Alcohol Studies.

Childress, A. R., McLellan, A. T., Natale, M., \& O'Brien, C. P. (1987). Mood states can elicit conditioned withdrawal and craving in opiate abuse patients. In L. S. Harris (Ed.), Problems in drug dependence (NIDA Research Monograph 76; pp. 137-144). Washington, DC: U.S. Government Printing Office.

Childress, A. R., McLellan, A. T., \& O’Brien, C. P. (1986). Abstinent opiate abusers exhibit conditioned craving, conditioned withdrawal and reductions in both through extinction. British Journal of Addictions, 81, $655-660$.

Collins, B. N., Copeland, A. L., Quinn, E. P., \& Brandon, T. H. (1994, November). Negative affect motivated smoking: Support from a multimodal assessment study. Poster presented at the meeting of the Association for the Advancement of Behavior Therapy, San Diego, CA.

Cooney, N. L., Baker, L. H., Pomerleau, O. F., \& Josephy, B. (1984). Salivation to drinking cues in alcohol abusers: Toward the validation of a physiological measure of craving. Addictive Behavior, 9, 91-94.

Cooney, N. L., Litt, M. D., Morse, P. A., Bauer, L. O., \& Gaupp, L. (1997). Alcohol cue reactivity, negative-mood reactivity, and relapse in treated alcoholic men. Journal of Abnormal Psychology, 106, 243-250.

Corty, E. W., \& Coon, B. (1995). The extinction of naturally occurring conditioned reactions in psychoactive substance users: Analog studies. Addictive Behaviors, 20, 605-618.

Cunningham, C. L. (1979). Alcohol as a cue for extinction: State dependency produced by conditioned inhibition. Animal Learning and Behavior, 7, 45-52.

Drummond, D. C., \& Glautier, S. P. (1994). A controlled trial of cue exposure treatment in alcohol dependence. Journal of Consulting and Clinical Psychology, 62, 809-817.

Drummond, D. C., Tiffany, S., Glautier, S., \& Remington, B. (Eds.). (1995). Addictive behaviour: Cue exposure theory and practice. New York: Wiley.

Gunther, L. M., Denniston, J. C., \& Miller, R. R. (1998). Conducting exposure treatment in multiple contexts can prevent relapse. Behaviour Research and Therapy, 36, 75-91.

Hanford, P. V., Mulvaney, D. E., \& Kelfer, D. A. (1980). The effect of novel environments on CS extinction in a conditioned suppression paradigm. Bulletin of the Psychonomic Society, 16, 341-344.

Kozlowski, L. T., Pillitteri, J. L., Sweeney, C. T., Whitfield, K. E., \& Graham, J. W. (1996). Asking questions about urges or cravings for cigarettes. Psychology of Addictive Behaviors, 10, 248-260.

Litt, M. D., Cooney, N. L., Kadden, R. M., \& Gaupp, L. (1990). Reactivity to alcohol cues and induced moods in alcoholics. Addictive Behaviors, $15,137-146$.

Lovibond, P. F., Preston, C. G., \& Mackintosh, N. J. (1984). Context specificity of conditioning, extinction, and latent inhibition. Journal of Experimental Psychology: Animal Behavior Processes, 10, 360-375.

Marlatt, G. A. (1985). Relapse prevention: Theoretical rationale and overview of the model. In G. A. Marlatt \& J. R. Gordon (Eds.), Relapse prevention (pp. 3-70). New York: Guilford Press.

McCusker, C. G., \& Brown, K. (1995). Cue-exposure to alcohol-associated stimuli reduces autonomic reactivity, but not craving and anxiety, in dependent drinkers. Alcohol and Alcoholism, 30, 319-327.

McLellan, A. T., Childress, A. R., Ehrman, R., O’Brien, C. P., \& Pashko, S. (1986). Extinguishing conditioned responses during opiate dependence treatment: Turning laboratory findings into clinical procedures. Journal of Substance Abuse Treatment, 3, 33-40.

Mermelstein, R., \& Lichtenstein, E. (1983). Conditioning phenomena and the problem of relapse in opioid addicts and alcoholics. In B. A. Ray (Ed.), Learning factors in substance abuse (pp. 161-179) [ Monograph]. National Institute of Drug Abuse.

Miller, R. R., \& Schachtman, T. R. (1985). The several roles of context at the time of retrieval. In P. D. Balsam \& A. Tomie (Eds.), Contexts and learning (pp. 167-194). Hillsdale, NJ: Erlbaum.

Mineka, S., Mystkowski, J., Hladek, D., \& Rodriguez, B. (1999). The effects of context on return of fear following exposure treatment of spider fears. Journal of Consulting and Clinical Psychology, 67, 599604.

Monti, P. M., Binkoff, J. A., Abrams, D. B., Zwick, W. R., Nirenberg, T. D., \& Liepman, M. R. (1987). Reactivity of alcoholics and nonalcoholics to drinking cues. Journal of Abnormal Psychology, 96, 122-126.

Monti, P. M., \& Rohsenow, D. J. (1999). Coping skills training and cue-exposure therapy in the treatment of alcoholism. Alcohol Research and Health, 23, 107-115.

Monti, P. M., Rohsenow, D. J., Rubonis, A. V., Niaura, R. S., Sirota, A. D., Colby, S. M., et al. (1993). Cue exposure with coping skills treatment for male alcoholics: A preliminary investigation. Journal of Consulting and Clinical Psychology, 61, 1011-1018.

Newlin, D. B., Hotchkiss, B., Cox, W. M., Rauscher, F., \& Li, T. K. (1989). Autonomic and subjective responses to alcohol stimuli with appropriate control stimuli. Addictive Behavior, 14, 625-630.

Niaura, R. S., Abrams, D., Shadel, W. G., Rohsenow, D. J., Monti, P. M., \& Sirota, A. D. (1999). Cue exposure treatment for smoking relapse prevention: A controlled clinical trial. Addiction, 94, 685-695.

Niaura, R. S., Rohsenow, D. J., Binkoff, J. A., Monti, P. M., Pedraza, M., 
\& Abrams, D. B. (1988). The relevance of cue reactivity to understanding alcohol and smoking relapse. Journal of Abnormal Psychology, 97, 133-152.

O’Brien, C. P., Childress, A. R., McLellan, T., \& Ehrman, R. (1990). Integrating systematic cue exposure with standard treatment in recovering drug dependence patients. Addictive Behaviors, 15, 355-365.

Pavlov, I. P. (1960). Conditioned reflexes. New York: Dover Publications. (Original work published in 1927).

Payne, T. J., Schare, M. L., Levis, D. J., \& Colletti, G. (1991). Exposure to smoking-relevant cues: Effects on desire to smoke and topographical components of smoking behavior. Addictive Behaviors, 16, 467-479.

Pead, J., Greeley, J., Ritter, A., Murray, T., Felstead, B., Mattick, R., \& Heather, N. (1993). A clinical trial of cue exposure combined with cognitive-behavioral treatment for alcohol dependence. Paper presented at the 55th meeting of the College on Problems of Drug Dependence, Toronto, Ontario, Canada.

Pomerleau, O. F., Fertig, J., Baker, L., \& Cooney, N. (1983). Reactivity to alcohol cues in alcoholics and non-alcoholics: Implications for a stimulus control analysis of drinking. Addictive Behavior, 8, 1-10.

Powell, J. (1995). Conditioned responses to drug-related stimuli: Is context crucial? Addiction, 90, 1089-1095.

Rankin, H., Hodgson, R., \& Stockwell, T. (1983). Cue exposure and response prevention with alcoholics: A controlled trial. Behaviour Research and Therapy, 21, 435-446.

Rodriguez, B. I., Craske, M. G., Mineka, S., \& Hladek, D. (1999). Contextspecificity of relapse: Effects of therapist and environmental context on return of fear. Behaviour Research and Therapy, 37, 845-862.

Rohsenow, D. J., Monti, P. M., Abrams, D. B., Rubonis, A. V., Niaura, R. S., Sirota, A. D., \& Colby, S. M. (1992). Cue elicited urge to drink and salivation in alcoholics: Relationship to individual differences. Advances in Behaviour Research and Therapy, 14, 195-210.

Rohsenow, D. J., Monti, P. M., Rubonis, A. V., Sirota, A. D., Niaura, R. S., Colby, S. M., et al. (1994). Cue reactivity as a predictor of drinking among male alcoholics. Journal of Consulting and Clinical Psychology, 62, 620-626.

Rohsenow, D. J., Niaura, R. S., Childress, A. R., Abrams, D. B., \& Monti, P. M. (1990-1991). Cue reactivity in addictive behaviors: Theoretical and treatment implications. International Journal of Addictions, 25, 957-993.

Rosenthal, R., \& Rosnow, R. L. (1985). Contrast analysis: Focused comparisons in the analysis of variance. New York: Cambridge University Press.

Siegel, S. (1983). Classical conditioning, drug tolerance, and drug dependence. In Y. Israel, F. B. Glaser, H. Kalant, R. E. Popham, W. Schmidt, \& R. G. Smart (Eds.), Research advances in alcohol and drug problems (Vol. 7, pp. 207-246). New York: Plenum.

Sitharthan, T., Sitharthan, G., Hough, M. J., \& Kavanagh, D. J. (1997). Cue exposure in moderation drinking: A comparison with cognitivebehavior therapy. Journal of Consulting and Clinical Psychology, 65, $878-882$.

Spear, N. E. (1973). Retrieval of memory in animals. Psychology Review, 80, 163-194.

Spear, N. E. (1981). Extending the domain of memory retrieval. In N. E. Spear \& R. R. Miller (Eds.), Information processing in animals: Memory mechanisms (pp. 341-378). Hillsdale, NJ: Erlbaum.

Stasiewicz, P. R., Gulliver, S. B., Bradizza, C. M., Torrisi, R., Rohsenow, D. J., \& Monti, P. M. (1997). Exposure to negative affect and reactivity to alcohol cues during cue exposure. Behaviour Research and Therapy, $35,1143-1149$.

Stewart, J., DeWit, H., \& Eikelboom, R. (1984). The role of conditioned and unconditioned drug effects in the self-administration of opiates and stimulants. Psychological Review, 9, 251-268.

Tiffany, S. T., \& Drobes, D. J. (1990). Imagery and smoking urges: The manipulation of affective content. Addictive Behaviors, 15, 531-539.

Tobeña, A., Fernandez-Teruel, A., Escorihuela, R. M., Nunez, J. F., Zapata, A., Ferre, P., \& Sanchez, R. (1993). Limits of habituation and extinction: Implications for relapse prevention programs in addictions. Drug and Alcohol Dependence, 32, 209-217.

Wikler, A. (1948). Recent progress in research on the neurophysiological basis of morphine addiction. American Journal of Psychiatry, 105, 329-338.

Wikler, A. (1965). Conditioning factors in opiate addiction and relapse. In D. I. Wilner \& G. G. Kassenbaum (Eds.), Narcotics (pp. 85-100). New York: Plenum.

Wise, R. A. (1988). The neurobiology of craving: Implication for the understanding and treatment of addiction. Journal of Abnormal Psychology, 97, 118-132.

Received February 7, 2001

Revision received June 20, 2001

Accepted June 27, 2001 